Revista de Economia Política, vol. 29, $n^{\circ} 1$ (113), pp. 114-132, janeiro-março/2009

\title{
Discutindo o papel do Programa Bolsa Família na decisão das eleições presidenciais brasileiras de 2006
}

\author{
ROSA MARIA MARQUES \\ MARCEL GUEDES LEITE \\ ÁQUILAS MENDES \\ MARIANA RIBEIRO JANSEN FERREIRA*
}

This paper investigates the relationship between the impact of Bolsa Família Program in the Brazilian population and the result of the presidential elections of 2006. The database involves municipal information provided by MDS, IBGE and TSE. To control the experiment, the eventual influences of other variables in the determination of this relationship had been studied. All those variables come from specific characteristics of the cities, such as: city with predominant urban or not urban population; size of the city population; among others. The results state that the Bolsa Família was, in fact, a very important factor in the determination of the votes in Lula. It was, in itself, responsible by $45 \%$ of the total votes in Lula.

Keywords: Bolsa Família; presidential elections of 2006; determinations of votes.

JEL Classification: I38; H53.

\footnotetext{
* Respectivamente, Professora Titular da PUCSP, líder do Grupo de Pesquisa Políticas para o Desenvolvimento Humano. E-mail: rosamarques@hipernet.com.br; Professor Doutor da PUCSP e do Mackenzie.E-mail: magle@uol.com.br; Professor de Economia da PUCSP e da FAAP/SP. E-mail: aquilasn@uol. com.br; Professora de Economia da PUCSP. E-mail: mariana.jansen@gmail.com. Todos membros do PPDH. Submetido: Maio 2007; Aprovado: Outubro 2007.
} 
"Na semana imediatamente posterior às eleições de 15 de novembro, ia eu num ônibus quase vazio e ouvia a conversa entre o motorista e o cobrador, às suas costas. Ambos nordestinos, comentavam os resultados eleitorais, quem ganhou, quem perdeu. A certa altura, o motorista fez a afirmação enfática: "Esse pessoal se engana com a gente. Na hora de votar, quem mora num barraco é igualzinho a Antônio Ermírio." (Gorender, 1995)

\section{À GUISA DE INTRODUÇÃO}

\section{Eleições, seus determinantes e objetivo}

A determinação dos fatores que atuam em um resultado eleitoral sempre foi algo difícil mesmo para aqueles que a tem como objeto de pesquisa. Entre os diferentes ramos da ciência que se ocupam do homem como um ser social, historicamente determinado, a ciência política e a sociologia têm destaque nos esforços empreendidos para explicar as características e os processos de representação partidária brasileira, com ênfase maior ou menor nas instituições, no funcionamento dos partidos, nas suas alianças e interesses, bem como nos fatores explicativos da opção por votar nesse ou naquele candidato, nesse ou naquele partido.

Os estudos sobre o sistema partidário brasileiro no período 1945-1964 podem ser classificados segundo três tipos de tese: desestruturação do sistema partidário; processo de bipolarização e tendência a realinhamento partidário (Lavareda, 1991, apud Rego, 1993). Para o período 1970-1979, Lamounier (1980) estudou a relação entre as avaliações do desempenho governamental na assistência médica do então Instituto Nacional de Assistência Médica da Previdência Social, custo de vida, acesso à casa própria via o Banco Nacional de Habitação, escola primária e policiamento, percebidas pelos eleitores paulistas, e sua preferência partidária. Os eleitores, por sua vez, foram divididos por nível de instrução. Essa pesquisa revelou que apenas para os eleitores com nível superior havia alguma correlação entre o desempenho da política governamental e a preferência partidária. Rodrigues debruçou-se sobre a composição ocupacional dos deputados federais para destacar "as diferenças partidárias quanto à representação dos interesses e suas relações com as respectivas ideologias" (Rodrigues, 2002: 32), concluindo que para o entendimento das diferenças entre os partidos deve-se levar em conta não somente a ideologia e a orientação política, mas também os segmentos sociais neles representados (idem: 42). Há ainda os que enfatizaram o papel da mídia e da opinião publica (Schmitt, C. et al., 1998) e os que trataram da centralidade da sofisticação no processo eleitoral (Castro, 1994). Na extensa literatura sobre o tema, destacam-se, ainda, Lima Junior (1999) e Pereira e Renno. O primeiro discute a centralidade, o contexto e as implicações das eleições e, os demais, quais são os atributos que levam à reeleição.

A referência a esses estudos - que constituem apenas uma amostra da extensa 
literatura acumulada no país sobre processo eleitoral, representação partidária e fatores determinantes dos votos - tem como objetivo salientar as diferentes abordagens e preocupações que nortearam esse objeto. Nesse sentido; não houve a intenção de se fazer uma revisão completa do conhecimento já existente.

Nas últimas eleições para presidente da República, realizadas em 2006, Luis Inácio Lula da Silva foi reeleito no $2^{\circ}$ turno com $60,8 \%$ dos votos válidos, isto é, com 58,3 milhões de votos. Depois de uma campanha centrada na ética e na denúncia da corrupção de elementos do governo e do Partido dos Trabalhadores, tanto pela oposição à direita como à esquerda, em que não faltaram novos fatos revelando inexplicáveis e patéticas tentativas de compra de informações sobre o candidato do Partido Social Democrata Brasileiro (PSDB) ao estado de São Paulo (um dos mais importantes do país, tanto economicamente como politicamente, com forte concentração da oposição), e uma ação concertada da mídia para que houvesse $2^{\circ}$ turno, como nunca antes se viu na história recente do país, Lula foi reeleito. Embora essa afirmação possa ser considerada um pouco forte, a apresentação de novos "fatos", às vezes mais do que diariamente, o que foi registrado pela revista Carta Capital, superou, em nosso entender, a edição realizada pela Rede Globo quando do debate entre Collor e Lula, em 1989. Além dessa revista, que abertamente manifestou preferência por Lula, diversos articulistas trataram do assunto, tais como Alberto Dines do Observatório da Imprensa, Marcelo Beraba, então ombudsman da Folha de São Paulo e Luis Nassif.

Em termos percentuais, Lula obteve um pouco menos de votos do que no $2^{\circ}$ turno de 2002 (61,27\%), quando foi eleito pela primeira vez. Mas dadas às condições em que seu governo se desenvolveu, a todo tempo convivendo com denúncias de corrupção, a ponto de seus mais destacados quadros terem sido afastados de seus cargos, tal resultado foi surpreendente. Em termos de distribuição dos votos, levando em conta a localização geográfica dos estados, essa eleição revelou um país dividido, onde Lula ganhou em 20 dos 27 estados existentes, sendo que destes, em todos da região Nordeste, a mais pobre do país; perdeu em apenas um estado da região Norte (a segunda mais pobre); e ganhou em três estados da região Sudeste e em dois da região Centro-Oeste, inclusive no Distrito Federal (DF), onde está localizada a capital do país. Enfim, perdeu em todos os estados da região Sul. Além disso, todas as pesquisas divulgadas ${ }^{1}$ pela mídia indicaram que quanto menor e mais pobre o município, maior foi sua votação, o mesmo ocorrendo em relação à renda dos votantes. A eleição revelou, segundo diversos analistas, um fato novo na realidade brasileira, a que os segmentos mais pobres da população, pertencentes às classes $\mathrm{C}$ e $\mathrm{D}$, não se sensibilizaram com a posição dos chamados formadores de opinião, especialmente a expressa pela imprensa escrita e televisiva. Durante a campanha presidencial e mesmo depois de realizada as eleições, a mí-

\footnotetext{
${ }^{1}$ Apenas a titulo de exemplo, cita-se matéria assinada por Jose Roberto de Toledo, da BBC Brasil. com, e divulgada na Folha On Line em 20 de outubro de 2006; Com o mesmo intuito, menciona-se a matéria de Marcelo de Morais, de 15 de outubro de 2006, divulgada pelo Estadão.
} 
dia, os chamados formadores de opinião e articulistas conceituados destacaram a importância do Programa Bolsa Família (PBF) na determinação do voto. Esse foi o caso de Bresser-Pereira (2006), mencionado mais adiante.

Pesquisa realizada em 2004 sobre o impacto desse programa nos municípios já apontava para a possibilidade de essa política de transferência de renda vir a criar e sustentar uma nova base de apoio ao presidente. Essa base de apoio, diferente daquela tradicional, fundada na organização sindical e nos movimentos sociais, seria dispersa e não organizada (Marques e Mendes, 2006). Essa hipótese derivava da abrangência do PBF em relação à população total de alguns municípios e do peso relativo dos recursos transferidos em relação à receita disponível dos municípios, isto é, a soma das receitas próprias com as transferências constitucionais (Marques et al., 2004).

Todavia, essa pesquisa analisou o momento inicial da implantação do PBF, quando este atingia "apenas" 4,3 milhões de famílias, a um custo de R \$ 3,6 bilhões ao ano, e adotou como metodologia, entre outros aspectos, um estudo amostral. Em nova pesquisa feita em 2006, pelos mesmos autores, o estudo abrangeu o universo dos municípios cobertos pelo PBF. Quando da eleição presidencial, o PBF beneficiava 11,01 milhões de famílias, ao custo de $\mathrm{R} \$ 8,2$ bilhões ao ano e atingindo, diretamente, $25,9 \%$ da população estimada pelo IBGE para 2006 (Marques et al., 2006).

De posse das informações e conclusões derivadas dessa pesquisa, testou-se a hipótese aventada em 2004 e comentada pela mídia durante o processo eleitoral de 2006, considerando os resultados para o cargo de presidente em cada município.

Sabemos que o resultado de uma eleição é produto de múltiplos fatores. Como diz Marx: "O concreto é concreto por ser a síntese de múltiplas determinações, logo, unidade da diversidade" (Marx, 1973: 231). Do ponto de vista da população de mais baixa renda, além do PBF, o governo Lula realizou uma série de atividades e/ou programas. Apenas a título de ilustração, destacamos o programa "Luz para todos" (lançado em 12/2003 e atingindo mais de um milhão de famílias ao final de $2006^{2}$ ), o Programa Nacional de Fortalecimento da Agricultura Familiar, cujos recursos aumentaram de R \$2,3 bilhões em 2003 (900 mil famílias) para R \$ 10 bilhões em 2006 ( 2 milhões de famílias ${ }^{3}$ ); o Programa Universidade para Todos, que

\footnotetext{
${ }^{2}$ Isso equivale a $50 \%$ das famílias rurais e de locais de difícil acesso que não tinham acesso à luz elétrica em 2003, quando o governo fez o levantamento do público-alvo.

${ }^{3}$ Além do garantir recursos para investimento e custeio das propriedades familiares, também passou a oferecer linhas de crédito para mulheres agricultoras, jovens que cursem escolas agrotécnicas, produtores assentados, entre outras. Segundo o Ministério do Desenvolvimento Agrário, a agricultura familiar engloba 4,2 milhões de estabelecimentos familiares, representa $84 \%$ dos estabelecimentos rurais, emprega $70 \%$ da mão de obra do campo e produz $68 \%$ da produção de alimentos consumida pela população brasileira (MDA, 2006). Vale dizer que Apesar dessa crítica mais geral, o Movimento dos Pequenos Agricultores (MPA), o MST, o Movimento dos Atingidos por Barragens (MAB), Movimento das Mulheres Camponesas (MMC), a Comissão Pastoral da Terra (CPT) e a Associação Brasileira de Reforma Agrária (ABRA), em documento apresentado em 03/2006, durante a conferência da Organiza-
} 
concede bolsa de estudo, integral ou parcial, para os egressos do ensino público, junto a faculdades privadas (em 2006 foram beneficiados 200 mil universitários); a redução dos impostos do cimento e dos alimentos de primeira necessidade. Além disso, o poder de compra do salário mínimo aumentou $40 \%$ e os movimentos sociais, principalmente os envolvidos com a luta pela reforma agrária, não sofreram repressão por parte do governo federal. Afora essas ações, outras realizadas pelo governo podem ter influído no voto da população mais pobre.

Vale esclarecer que não estamos aqui defendendo que necessariamente políticas dirigidas à população mais pobre garantam a fidelidade no momento do voto aos políticos que as implementaram e tampouco que as condições socioeconômicas determinem a orientação ideológica do voto. Sobre esse último aspecto, vários estudos já demonstraram, para eleições passadas, a inexistência de relação entre pobreza e voto em partido que se manifeste ideologicamente na defesa de um programa dirigido preferencialmente para esse segmento da população. Carreirão, por exemplo, para as eleições de 1989, 1994 e 1998, concluiu que dois determinantes se destacam: a imagem formada pelos eleitores dos candidatos e dos partidos; e a avaliação que fazem dos atributos dos candidatos, para a qual a mídia influencia (Carreirão, 2002).

Dessa forma, as eleições de 2006 teriam contrariado essas determinações, embora se possa dizer que o papel da mídia foi bastante importante para a realização de um $2^{\circ}$ turno ${ }^{4}$. Nesse caso, como mencionado anteriormente, houve fortes indicações que o segmento beneficiado pela política de transferência de renda influiu nos resultados para presidente da República. Para esses segmentos, como se verá adiante, não se trata de uma "imagem", e sim de uma política concreta que lhes beneficia, embora ela seja passível de críticas por sua limitação e natureza ${ }^{5}$.

Caberia um último reparo. É sabido que os resultados de um $2^{\circ}$ turno são influenciados por outras variáveis, tais como as coligações dos candidatos majoritários, entre outras. Contudo, tendo em vista a "fidelidade" dos votos em Lula, muito embora ele tenha aumentado sua votação no $2^{\circ}$ turno, inclusive retirando votos obtidos de seu oponente no $1^{\circ}$ turno, a hipótese levantada mantém sua pertinência.

\section{A percepção da mídia e de alguns articulistas sobre as eleições de 2006}

No período anterior às eleições, praticamente toda a mídia e os formadores de opinião consideravam que os escândalos que se avolumaram ao longo do pri-

ção das Nações Unidas para a Agricultura e Alimentação (FAO), consideram essa política um dos pontos positivos do governo Lula (Stedile, 2007).

${ }^{4}$ A hipótese aqui levantada é de que parte dos eleitores se sensibilizou com as denúncias de compra pelo PT de informações sobre o candidato do PSDB a governador em São Paulo, votando, no $1^{\circ}$ turno em Alkimin. Esses teriam mudado seu voto no $2^{\circ}$ turno. Essa hipótese é reforçada pelo fato de esse candidato ter recebido menos votos no $2^{\circ}$ do que no $1^{\circ}$ turno.

${ }^{5}$ Este artigo não analise os limites e os problemas do PBF. Para isso ver Marques e Mendes (2005). 
meiro mandato de Lula teriam minado a imagem do presidente e de seu partido. Contudo, na medida em que o pleito se aproximava, passou a vigorar a idéia de que Lula não só havia conseguido se dissociar dos escândalos e denúncias, mantendo sua popularidade e imagem junto aos eleitores, como também havia conformado um movimento batizado de "lulismo", como se as idéias e concepções do presidente "tivessem vida própria", dissociadas do partido e de sua equipe.

A "crise da corrupção" começou no início de 2004 quando Waldomiro Diniz, ex-assessor da Casa Civil, foi flagrado em vídeo negociando propina com um empresário do ramo de jogos. Depois de muitas idas e vindas, foi criada uma Comissão Parlamentar de Inquérito - $\mathrm{CPI}^{6}$, a qual chegou a abarcar temas que não estavam na sua pauta inicial, tornando-se base de investigação de diversas denúncias feitas contra o governo ou o PT, tais como a suposta ligação entre o assassinato do prefeito Celso Daniel (PT) e o esquema de financiamento de campanhas; as possíveis irregularidades na Prefeitura de Ribeirão Preto durante a gestão de Antonio Palocci (na época, ministro da Fazenda); a suposta doação de casas de bingo ou a remessa de dólares vindos de Cuba para a campanha de Lula, entre outros. Em maio de 2005, uma fita de vídeo mostrando um ex-funcionário dos Correios negociando propina com empresários interessados em participar de uma licitação deu origem à CPI dos Correios", cujo objeto foi a investigação do "suposto" esquema do "mensalão", que envolvia denúncias de corrupção nas estatais. As sessões das duas CPI eram transmitidas para todo o Brasil via a TV Câmara, e, durante bastante tempo, acompanhadas "on-line" pela população de todos os estratos sociais. Essas não foram as únicas situações relacionadas à corrupção que envolveu membros da equipe de governo e/ou do PT. Houve, por exemplo, em 2006 a criação da CPI das Sanguessugas, que tratava da chamada máfia das ambulâncias, envolvendo parlamentares e membros do Executivo.

O último escândalo envolvendo o governo ocorreu 15 dias antes do $1^{\circ}$ turno, quando a política federal revelou a tentativa de compra, por integrantes do PT, de um dossiê que envolvia o candidato ao governo de São Paulo, José Serra. Presos com R \$ 1,7 milhão sem origem declarada, esse fato resultou no afastamento de Ricardo Berzoini, ex-ministro e então coordenador da campanha de Lula. Este escândalo é considerado como aquele que maior prejuízo causou à reeleição de Lula ainda no $1^{\circ}$ turno. A proximidade da eleição e a divulgação das fotos do dinheiro que seria utilizado para compra do dossiê nos instantes finais da campanha, juntamente com a ausência do presidente Lula no debate final da TV Globo, criaram um cenário negativo para uma vitória já no $1^{\circ}$ turno. Segundo a mídia e os formadores de opinião, isso teria conformado, por parte dos eleitores, a percepção de criminalidade e falta de ética do PT e de seu candidato. Contudo, no $2^{\circ}$

\footnotetext{
${ }^{6} \mathrm{O}$ relatório final dessa CPI não foi conclusivo a respeito das denúncias.

${ }^{7}$ Essa CPI revelou um esquema de distribuição de recursos a parlamentares, os quais os utilizariam, teoricamente, para bancar despesas de campanhas eleitorais. Como resultado, foram apresentados 124 nomes para serem indiciados pelo Ministério Público.
} 
turno, o presidente não só saiu vitorioso como os votos de seu oponente diminuíram em 2 milhões em relação aos obtidos no $1^{\circ}$ turno. Tanto isso é verdade que, no $1^{\circ}$ turno, Lula perdeu para Geraldo Alckmin - candidato pelo PSDB - em todos os estados da região Sul e da região Centro-Oeste (incluindo o DF), e ainda nos estados de São Paulo, Acre, Roraima e Rondônia. No $2^{\circ}$ turno, no entanto, Alckmin somente venceu em apenas sete estados (Rio Grande do Sul, Santa Catarina, Paraná, São Paulo, Mato Grosso, Mato Grosso do Sul e Acre).

Bresser-Pereira considera que a queda dos votos direcionados para Lula às vésperas do $1^{\circ}$ turno, e que possibilitou a ocorrência do segundo, foi fruto da indignação geral causada pelo dossiê contra os adversários e pelo não comparecimento do petista aos debates. Segundo ele, no $1^{\circ}$ turno, a segmentação social no voto entre Lula e Alckmin foi muito clara; os muito ricos e os pobres direcionaram seus votos para Lula; a classe média votou em Alckmin. Teria sido o resultado eleitoral mais polarizado que já ocorreu, mas, também, o mais "esquizofrênico": polarizada porque os pobres e os pouco educados votaram em um candidato, e os remediados e educados, em outro; esquizofrênica porque os muito ricos votaram com os pobres e os miseráveis (Bresser-Pereira, 2006). Tal segmentação teria bases econômicas muito sólidas, na visão de Bresser, tendo em vista que a população mais pobre vinculou seu voto aos benefícios que recebeu com o aumento do salário mínimo e a expansão do $\mathrm{PBF}$, enquanto os muitos ricos foram privilegiados por juros extremamente elevados.

A manutenção da intenção do voto em Lula pelos segmentos mais pobres da população no $2^{\circ}$ turno, e inclusive a diminuição dos votos de seu oponente, deixou grande parte da mídia e dos formadores de opinião sem saber o que dizer. No entanto, de acordo com Santos (2006), tal perplexidade é um sinal claro da pouca percepção que esses tiveram com relação à separação que existe entre uma elite política distante e arrogante e a "acumulação histórica de ressentimento que isso criou entre as classes populares" (idem: 3 ). Santos também enfatiza que a vitória de Lula deve-se ao que ele simboliza, além de sua capacidade de ampliar o impacto político de medidas paliativas, proporcionando uma percepção de melhoria de vida para milhões de brasileiros. Para ele essa capacidade é que fez com que programas como o PBF, que geram pequenas transferências de renda, possam ser percebidos como um processo de mudança qualitativa na vida das pessoas beneficiadas. Para esse autor:

"Tudo isso foi possível devido a uma sutil inversão do sinal político: atribuído por Lula, o Bolsa Família foi entendido pelos brasileiros como 'isso é o mínimo que vos devo'; fosse atribuído por um presidente de direita, dissesse o que dissesse, seria sempre entendido como 'isso é o máximo que vos devo"” (Santos, 2006).

Como afirmado anteriormente, não se trata de uma "percepção" sem fundamento. Conforme Gabriel Ulyssea (2006), técnico do Instituto de Pesquisa Aplicada, no caso das famílias beneficiárias do PBF, os recursos recebidos podem representar $40 \%$ da renda familiar, sendo que, na média do Brasil, recebem $\mathrm{R} \$ 62,00$. Como é sabido, empiricamente, que pessoas vivendo abaixo da linha de pobreza dirigem praticamente todo o acréscimo de renda para a compra de alimentos. Mas 
existem pesquisas que comprovam esse conhecimento "popular". Para se ter uma idéia, estudo sobre o impacto de outros programas de transferência de renda mostrou que, para famílias com renda mensal per capita inferior a $\mathrm{R} \$ 90,00$, para cada 1 real $(\mathrm{R} \$ 1,00)$ de benefício recebido, 89 centavos são gastos em alimentos (MS, 2003).

\section{METODOLOGIA DE ANÁLISE}

Para investigar se o PBF teve impacto sobre as decisões eleitorais para a Presidência da República de 2006, foram analisadas as eventuais relações entre a cobertura do PBF em relação à população total e os votos recebidos por Lula.

Para a obtenção do grau de cobertura do PBF em relação à população total foram utilizados os dados do número de famílias beneficiárias do PBF em outubro de 2006 (Ministério do Desenvolvimento Social e Combate à Fome - MDS) e as informações da população estimada para os municípios brasileiros em 2006 (Instituto Brasileiro de Geografia e Estatística - IBGE). A estimativa da população beneficiária do PBF foi obtida multiplicando-se o número de famílias beneficiárias por 4,4 (tamanho médio das famílias pobres, em 2006, segundo a Secretaria Nacional de Renda e Cidadania do MDS). Assim, o número de famílias beneficiárias em cada município do país, multiplicado por 4,4 e dividido pela população total estimada para cada município, gerou o Grau de Cobertura do PBF para todos os municípios brasileiros.

Os graus de cobertura foram calculados para 5560 municípios, pois dos 5564 constantes do banco de dados fornecido pelo MDS, para quatro não há informação sobre o número de famílias beneficiárias. A ausência desses municípios não prejudica, contudo, o estudo, pois aos 5560 municípios considerados, onde 11.009.341 famílias são beneficiárias, corresponde a 186.758.424 habitantes, ou seja, quase à totalidade da população estimada pelo IBGE para o Brasil, de 186.770.562 habitantes, em 2006.

A opção por trabalhar com a população total e não com a população-alvo do PBF (pobre), deveu-se aos seguintes motivos: a) o eleitorado refere-se à parcela da população total e não apenas à população-alvo; b) não há informações oficiais do voto por faixa de renda, a não ser aquelas resultantes de pesquisas realizadas anteriormente ao pleito, por diferentes fontes, o que, de fato, na melhor das hipóteses, indicava estimativas de intenção do voto, não sendo, portanto, oficiais; e c) porque se reconhece que os efeitos do PBF não se restringem às famílias beneficiárias, sendo percebidos pelo restante da comunidade a que essas famílias pertencem em função de sua maior ou menor cobertura em relação à população total. Esse reconhecimento pode ser tanto fruto de relações pessoais como da observação empírica de seu efeito sobre o consumo local, principalmente do aumento do consumo de alimentos. A hipótese aqui adotada é de que essa percepção pode influenciar na decisão do voto.

A relação do grau de cobertura (sobre a população total) com a porcentagem 
dos votos válidos recebidos por Lula foi analisada em três níveis: municipal, estadual e por grandes regiões geográficas. A fim de verificar se este resultado poderia ser influenciado por outras características dos municípios brasileiros, que não o nível de pobreza (posto que o PBF é dirigido exatamente ao segmento mais pobre da população), isto é, se não existe correlação espúria, foram consideradas algumas dessas possíveis características. A investigação se deu inicialmente através de regressões simples entre cada uma destas características e o grau de cobertura, a fim de identificar a existência de uma relação estatisticamente aceitável ou não entre elas.

Primeiramente foi analisada a distribuição do coeficiente de participação do eleitorado na população total a fim de observar se não existem diferenças tanto entre os estados como dos municípios. Caso fossem detectadas essas diferenças, isso poderia distorcer a interpretação dos resultados obtidos no estudo. Para tanto, os estados foram distribuídos segundo faixas de participação do eleitorado na população total nos seguintes intervalos: até $60 \%$; de $60 \%$ a $65 \%$; de $65 \%$ a $70 \%$; e acima de $70 \%$, haja vista a elevada concentração dos estados em torno da média nacional de $67,4 \%$. Já os municípios foram distribuídos nos seguintes intervalos: até $60 \%$, seguido de intervalos consecutivos de amplitude de $5 \%$, até o último, acima de $90 \%$. O maior número de faixas atribuídas aos municípios se deve à maior dispersão desta participação entre estes do que a existente entre os estados.

Em segundo lugar, verificou-se se o comportamento do relacionamento entre os dois indicadores não estaria associado ao porte populacional dos municípios, pois, tal qual assumido no tratamento anterior, caso esta relação fosse observada, então eventuais relações percebidas entre os indicadores propostos poderiam estar influenciadas pelo porte populacional do município, superpondo-se à relação em si. Na definição dos portes populacionais, adotou-se a mesma metodologia utilizada nas pesquisas sobre o PBF feitas em 2004 e em 2006 (Marques et. al., 2004, 2006), agrupando os municípios em quatro categorias: pequenos (até 20 mil habitantes em 2006), médios (de 20 mil a 100 mil habitantes), grandes (de 100 mil a 500 mil habitantes) e muito grandes (acima de 500 mil habitantes).

Também se analisou se a caracterização dos municípios como rural ou urbano, assim como a distribuição deles entre capital, região metropolitana e interior, poderiam induzir uma relação sistemática entre o grau de cobertura do PBF e os votos recebidos pelo presidente Lula. Na definição do município como predominantemente rural ou urbano não foram incluídos 88 municípios, por terem sua população igualmente distribuída entre essas duas categorias. Assim, estes municípios foram incorporados na média estadual e da Região Geográfica, mas não tratados isoladamente. Para as Regiões Metropolitanas, somente foram consideradas aquelas criadas em 1973, por Lei Complementar Federal, sendo desconsideradas todas as demais Regiões Metropolitanas criadas por Lei Complementar Estadual depois desta data. Estas não foram analisadas por apresentarem ainda certo grau de dificuldade para se integrarem como área de administração comum, ou como em muitos casos, por serem ainda muito recentes, com graus de integração muito diferenciados. Foram estudadas as Regiões Metropolitanas de Belém, de Fortale- 
za, do Recife, de Salvador, de Belo Horizonte, do Rio de Janeiro, de São Paulo, de Curitiba e de Porto Alegre. Na Região Metropolitana não foram incluídas as capitais, pois estas foram analisadas em separado.

Por fim, foram contempladas ainda outras três variáveis: a influência da prefeitura ser conduzida por um prefeito do PT ou não; o IDH municipal; e a renda per capita municipal em 2005 (último dado disponibilizado pelo IBGE). Como não foi possível encontrar qualquer relação significativa entre esta última variável e o grau de cobertura do PBF, optou-se por tratar a variável como qualitativa pobres, municípios com renda per capita inferior a $\mathrm{R} \$ 6.000,00$; ricos, os municípios com renda per capita acima de $\mathrm{R} \$ 24.000,00$ e medianos, aqueles com renda entre estes dois níveis. As outras duas variáveis também foram tratadas como variáveis qualitativas, sendo que os municípios foram divididos em acima e abaixo da média nacional para o IDH-M.

Para controlar a capacidade explicativa da cobertura do PBF em relação à população total sobre o resultado da eleição presidencial de 2006, realizou-se uma regressão múltipla incorporando, além deste fator, a renda per capita ("pobre", "intermediário" e "rico"); IDH-M abaixo e acima da média nacional; município rural ou urbano; município com prefeitura do PT ou não; porte populacional do município; localização do município; e participação do eleitorado na população total.

A análise a nível estadual limitou-se às variáveis: grau de cobertura, participação do eleitorado na população total e a renda per capita do estado, haja vista as demais se referirem a características municipais e não estaduais.

\section{RESULTADOS OBTIDOS}

\section{Variáveis de controle}

Para evitar a possibilidade de uma relação espúria entre a cobertura do PBF e os votos em Lula, foi investigado se algumas variáveis poderiam influenciar a opção do voto no mesmo sentido da cobertura do PBF. Caso esta relação se confirmasse, então a influência do PBF nas eleições não ficaria claramente caracterizada, podendo induzir a uma conclusão frágil devido a essa superposição de causalidade ${ }^{8}$.

$\mathrm{Na}$ elaboração das relações, os percentuais de cobertura do PBF mostrados

\footnotetext{
${ }^{8}$ A não inclusão da renda como variável de controle se deve ao fato de constituir a própria lógica de distribuição do PBF: o atendimento a populações de baixa renda. Com isso, espera-se que os municípios com maior grau de cobertura devem ser necessariamente os municípios mais pobres. Há, portanto, uma elevada correlação entre a variável alvo de investigação (grau de cobertura) e o nível de renda do município, tornando redundante a inclusão desta variável no modelo de investigação Entretanto, como salientado anteriormente, a análise do voto por classe de renda torna-se inviável na medida em que essas informações não existem e o alcance da importância do PBF extrapola os beneficiários diretos, alcançando toda a população que toma conhecimento dos benefícios permitidos pelo ele, o que certamente encontra-se mais diretamente ligado ao grau de cobertura do PBF.
} 
nas Tabelas 1 a 5 estão associados às faixas das variáveis controle em questão. Para exemplificar, entre os municípios cuja participação do eleitorado na população total é menor que $60 \%$, há uma cobertura média de $34 \%$ do PBF, e uma média de $68 \%$ de votos no Lula, e assim por diante. Isso não significa que entre os municípios com esse grau de cobertura tenhamos essa mesma incidência de votos. As análises permitiram concluir pela não existência de superposição de influência, evidenciando, assim, que os resultados obtidos pelas avaliações da relação entre o PBF e os votos nas eleições de 2006 ganham robustez e confiabilidade.

\section{Participação dos eleitores na população total}

Conforme pode ser observado na Tabela 1, é percebida alguma relação (estatisticamente não significativa) entre a participação do eleitorado na população total e a proporção dos votos válidos em Lula no $2^{\circ}$ turno das eleições de 2006. No entanto, a mesma sistematicidade não é encontrada quando se compara aquela variável com o grau de cobertura do PBF na população total. Assim, uma vez que não se observa um comportamento sistemático e simultâneo entre as três variáveis, qualquer influência da cobertura do PBF no resultado eleitoral de 2006 não é induzida pelo peso do eleitorado na população total dos estados.

Tabela 1

Grau de cobertura do PBF e votos recebidos por Lula (v/vv) no $2^{\circ}$ turno das eleições de 2006 , nos estados brasileiros por faixa de participação do eleitorado na população total -\%

\begin{tabular}{c|ccc}
\hline eleitorado / população & no de estados & $\begin{array}{c}\text { cobertura } \\
\text { PBF }\end{array}$ & v/vv \\
\hline até 60\% & 4 & 26,7 & 64,0 \\
de 60\% a 65\% & 4 & 40,1 & 63,4 \\
de 65\% a 70\% & 14 & 31,8 & 63,2 \\
mais de 70\% & 5 & 23,4 & 60,0 \\
\hline
\end{tabular}

Fonte: TSE, MDS e IBGE. Elaboração própria.

A mesma análise foi feita para os municípios, e, como pode ser visto na Tabela 2, apesar de existir uma forte correlação direta entre a participação do eleitorado na população total e o grau de cobertura do PBF, o mesmo não ocorre entre aquela variável e a porcentagem de votos em Lula no $2^{\circ}$ turno das eleições de 2006. Nos municípios pertencentes às faixas de menor proporção de eleitores nas suas respectivas populações, observa-se uma relação inversa entre o grau de cobertura e os votos recebidos. Entretanto, já a partir da quarta faixa (de $70 \%$ a $75 \%$ ), essa relação é absolutamente inexistente. Mais uma vez se observa, que esse grau de cobertura está associado às faixas de participação do eleitorado no total da população, não podendo, portanto, nada ser concluído da leitura pura e simples das colunas 2 e 3 da Tabela 2. 
Tabela 2

Grau de cobertura do PBF e votos recebidos por Lula (v/vv) no $2^{\circ}$ turno das eleições de 2006 , nos municípios brasileiros por faixa de participação do eleitorado na população total -\%

\begin{tabular}{c|ccc}
\hline eleitorado / população & no de municípios & $\begin{array}{c}\text { cobertura } \\
\text { PBF }\end{array}$ & v/vv \\
\hline até 60\% & 463 & 34,4 & 68,2 \\
de 60\% a 65\% & 482 & 36,6 & 64,6 \\
de 65\% a 70\% & 865 & 37,1 & 62,4 \\
de 70\% a 75\% & 1171 & 37,4 & 60,8 \\
de 75\% a 80\% & 1084 & 39,1 & 60,1 \\
de 80\% a 85\% & 735 & 40,9 & 60,5 \\
de 85\% a 90\% & 363 & 45,2 & 60,9 \\
mais de 90\% & 397 & 53,8 & 61,8 \\
\hline
\end{tabular}

Fonte: TSE, MDS e IBGE. Elaboração própria.

\section{Porte populacional dos municípios}

Do ponto de vista intuitivo e lógico, espera-se que municípios de maior porte populacional apresentem maior oferta de oportunidades de emprego e geração de renda que os menores, uma vez que os maiores geralmente têm uma estrutura de produção e distribuição mais complexa. Neste sentido, apesar de existirem muitas exceções, pode-se imaginar que os municípios menores poderiam ser proporcionalmente mais pobres que os maiores e, por isso, apresentarem maior grau de cobertura do PBF que estes últimos. Como se sabe que existe estreito vínculo entre pobreza e cobertura do PBF (pois a pobreza é a razão da existência do PBF), investigou-se a possibilidade dos votos recebidos por Lula serem mais intensos quanto menor o porte populacional do município. Para tanto, os municípios foram distribuídos e classificados em quatro categorias de porte populacional: pequenos, médios, grandes e muito grandes.

Entretanto, como mostra a Tabela 3, apesar de aparentemente se confirmar a existência de correlação direta entre o porte populacional e o grau de cobertura do PBF na população total, não se percebe qualquer associação sistemática entre o tamanho da população do município e a votação em Lula, dado que a porcentagem dos votos válidos recebidos por ele é quase a mesma em qualquer dos portes populacionais estudados. 


\section{Tabela 3}

Grau de cobertura do PBF na população total e votos recebidos por Lula (v/vv) no $2^{\circ}$ turno das eleições de 2006 , nos municípios brasileiros, por porte populacional - \%

\begin{tabular}{c|cc}
\hline porte populacional & cobertura PBF & v/vv \\
\hline pequeno & 42,0 & 61,5 \\
médio & 36,4 & 63,5 \\
grande & 19,6 & 60,3 \\
muito grande & 16,0 & 63,0 \\
\hline Brasil & 25,9 & 60,8 \\
\hline
\end{tabular}

Fonte: TSE, MDS e IBGE. Elaboração própria.

Obs.: pequeno $=$ até 20 mil hab.; médio $=$ de 20 mil a 100 mil hab.;

grande $=$ de 100 mil 500 mil hab. e muito grande = maior que 500 mil hab .

\section{Municípios predominantemente rurais ou urbanos}

Assim como na análise das variáveis de controle anteriores, também foi alvo de preocupação deste estudo a investigação de possíveis associações sistemáticas entre o grau de cobertura do PBF e a característica predominante do município ser rural ou urbano. Entretanto, no caso brasileiro, esta associação mais intensa do meio rural com a pobreza pode até ser aceitável para os estados das regiões Norte e Nordeste, mas é bastante questionável nos estados da região Sul e, principalmente, Centro-Oeste. Nesta última, há predominância da atividade agropecuária sobre o setor industrial na geração de renda dos seus municípios, fazendo com que o interior necessariamente não se caracterize como predominantemente mais pobre que as capitais.

Conforme a Tabela 4, os valores do grau de cobertura do PBF na população total e da proporção dos votos válidos obtidos por Lula, associados à média dos municípios predominantemente rurais e os urbanos, são diferentes. Contudo, ao se testar a significância dessas diferenças (observadas tanto para a cobertura como para a proporção de votos em Lula), concluiu-se que, a 5\% de significância, os valores são indiferentes, isto é, iguais.

Tabela 4

Grau de cobertura do PBF na população total e votos válidos recebidos por Lula (v/vv) no $2^{\circ}$ turno das eleições de 2006, nos municípios brasileiros, por predominância rural ou urbana - \%

\begin{tabular}{c|cc}
\hline predominância & cobertura PBF & $\mathrm{v} / \mathrm{vv}$ \\
\hline rural & 48,9 & 68,8 \\
urbano & 22,3 & 59,6 \\
\hline
\end{tabular}

Fonte: TSE, MDS e IBGE. Elaboração própria.

Obs.: Valores de t calculado são 1,29 e 0,55, respectivamente, enquanto os valores críticos tendem a 1,96 (5\% de significância) e a 1,65 (10\% de significância). 
Desta forma, estatisticamente não se configura a indução de uma possível associação entre a cobertura do $\mathrm{PBF}$ e o resultado das eleições de 2006 provocada pelo fato de o município ser predominantemente rural ou urbano.

\section{Capital, região metropolitana e interior}

A característica de o município ser capital de estado, participante de região metropolitana ou do interior também foi analisada para se verificar se ela não condiciona a relação dos votos em Lula com a cobertura do PBF. Esta preocupação advém do senso comum que entende que a capital, ao se constituir sede do poder político dos estados, geralmente atua como pólo de atração de atividades econômicas, enquanto nos municípios do interior predomina a dispersão destas atividades. Assim, os municípios das capitais seriam relativamente mais ricos que os do interior e, conseqüentemente, teriam menor grau de cobertura do PBF. Já os municípios pertencentes às regiões metropolitanas, por estarem bastante associados às atividades econômicas das capitais, deveriam apresentar grau de cobertura intermediário entre o esperado para as capitais e os municípios do interior.

De fato, os valores médios de cobertura do PBF na população total das três categorias são aparentemente diferentes, comportando-se como o esperado pelo senso comum: $18,6 \%$ para as capitais, $23,2 \%$ para as regiões metropolitanas e $40,2 \%$ para o interior. No entanto, o fato de pertencer a um desses grupos especificados não confere nenhum comportamento sistemático que seja previsível, haja vista os coeficientes de votos válidos obtidos por Lula no $2^{\circ}$ turno das eleições de 2006 não serem diferentes entre os três grupos analisados. Além disso, testou-se a significância da diferença entre as coberturas do interior e da capital e concluiu-se não haver diferença significativa entre os valores para margens de erro de $5 \%$ (Tabela 5).

Tabela 5

Grau de cobertura do PBF e votos recebidos por Lula (v/vv) no segundo turno das eleições de 2006, entre os municípios brasileiros, segundo capital, região metropolitana e interior - \%

\begin{tabular}{c|cc}
\hline categoria & cobertura PBF & $\mathrm{v} / \mathrm{vv}$ \\
\hline capital & 18,6 & 61,2 \\
região metropolitana & 23,2 & 65,6 \\
interior & 40,2 & 61,8 \\
\hline
\end{tabular}

Fonte: TSE, MDS e IBGE. Elaboração própria.

Obs.: Valores de t calculado para diferenças de médias de cobertura e votos em Lula, para capital e interior são 1,00 e 0,03 respectivamente, enquanto os valores críticos tendem a 1,96 (5\% de significância) e a 1,65 (10\% de significância).

\section{IDH-M e renda per capita do município}

A análise da importância do IDH municipal no resultado eleitoral, conforme definida na metodologia acima, indicou uma correlação negativa, isto é, municí- 
pios com IDH abaixo da média nacional apresentaram maior proporção de votos em Lula. O inverso se observou para os municípios com IDH acima da média.

A capacidade explicativa da renda per capita não foi observada quando relacionamos diretamente o valor de cada município com o resultado eleitoral por ele apresentado. Contudo, ao tratarmos qualitativamente essa variável (agrupando os municípios em três tipos: ricos, com renda per capita superior a $\mathrm{R} \$ 24.000,00$; pobres, com valor inferior a $\mathrm{R} \$ 6.000,00$; e os demais considerados no nível intermediário) sua capacidade explicativa se evidenciou. Para os municípios "pobres" observou-se relação direta com os votos em Lula, enquanto para os "ricos" ela foi inversa.

Esses dois fatores foram os únicos relativamente capazes de explicar, isoladamente, o resultado da eleição $(30,3 \%$ e $38,8 \%)$, afora o grau de cobertura analisado abaixo, embora em proporção expressivamente menor.

\section{Administração municipal petista}

Apesar de o senso comum dizer que Lula seria beneficiado em municípios administrados por um prefeito do PT, a relação obtida foi inversa. Embora essa relação seja estatisticamente confiável, sua capacidade explicativa foi de apenas $0,3 \%$.

Cobertura do Bolsa Família sobre a população total e percentagem de votos válidos recebidos por Lula no $2^{\circ}$ turno das eleições de 2006

Uma vez não encontrada nenhuma sistematicidade significativa de influência das variáveis-controle sobre o vínculo do PBF com os resultados da eleição presidencial de 2006, investigou-se a existência de relação entre essas duas últimas variáveis.

Analisando-se essa associação nas regiões geográficas, observa-se forte relação direta entre o PBF e o resultado do pleito (Tabela 6). Conforme o grau de cobertura cresce, aumenta também a proporção de votos recebidos por Lula. A única exceção é verificada na região Sudeste, a qual, apesar de um coeficiente de cobertura um pouco inferior ao da região Sul, apresentou proporção de votos em Lula substancialmente superior ao da região Sul. Tal fato indubitavelmente se deve ao estado do Rio de Janeiro, onde Lula recebeu quase $70 \%$ dos votos válidos no $2^{\circ}$ turno, isto é, mais de 5,5 milhões de votos. No caso específico dessas eleições, Rio foi onde a candidata Heloísa Helena, da Frente de Esquerda, foi mais votada $(17,3 \%)$. Embora sua direção não tenha apoiado Lula no $2^{\circ}$ turno, seus eleitores, em quase sua totalidade, nele votaram. 
Tabela 6

Grau de cobertura do PBF na população total e proporção de votos válidos em Lula (v/vv) no $2^{\circ}$ turno das eleições de 2006, nas regiões geográficas - \%

\begin{tabular}{l|cc}
\hline Região & cobertura PBF & v/vv \\
\hline Nordeste & 56,0 & 77,1 \\
Norte & 30,3 & 65,6 \\
Centro_Oeste & 24,1 & 52,4 \\
Sul & 17,0 & 46,5 \\
Sudeste & 16,6 & 56,9 \\
\hline Brasil & 25,9 & 60,8 \\
\hline
\end{tabular}

Fonte: TSE, MDS e IBGE. Elaboração própria.

A análise para os estados confirmou a associação sistemática da cobertura do PBF com os votos em Lula no $2^{\circ}$ turno (Gráfico 1). Apesar de se observar alguma dispersão, a tendência linear ascendente na relação entre as variáveis estudadas é visível e estatisticamente confirmada, a $5 \%$ de significância. Este fator foi o único, entre os mencionados na metodologia, que apresentou significância estatística.

\section{Gráfico 1: Relação do grau de cobertura do Bolsa Família na população total e votos válidos em Lula no segundo turno das eleições de 2006, nos estados - \%}



Fonte: STE e MDS.

Levando essa investigação para a totalidade dos municípios, a influência direta do grau de cobertura do PBF na proporção de votos válidos recebidos por Lula nas eleições de 2006 permaneceu muito evidente, a despeito da grande dispersão existente especialmente entre os municípios com graus de cobertura menores (Gráfico 2). Para aprofundar a análise, os municípios foram distribuídos em faixas de cobertura para verificar a relação entre as médias dos graus de cobertura entre municípios indiferentes (para esse conceito). Os resultados obtidos surpreenderam 
por sua robustez, confirmando a hipótese básica que originou esse estudo, de haver uma relação direta entre o PBF e o resultado das eleições presidenciais de 2006 (Gráfico 3).

\section{Gráfico 2}

Relação do grau de cobertura do Bolsa Família na população total e votos válidos em Lula no segundo turno das eleições de 2006, para todos os municípios - \%

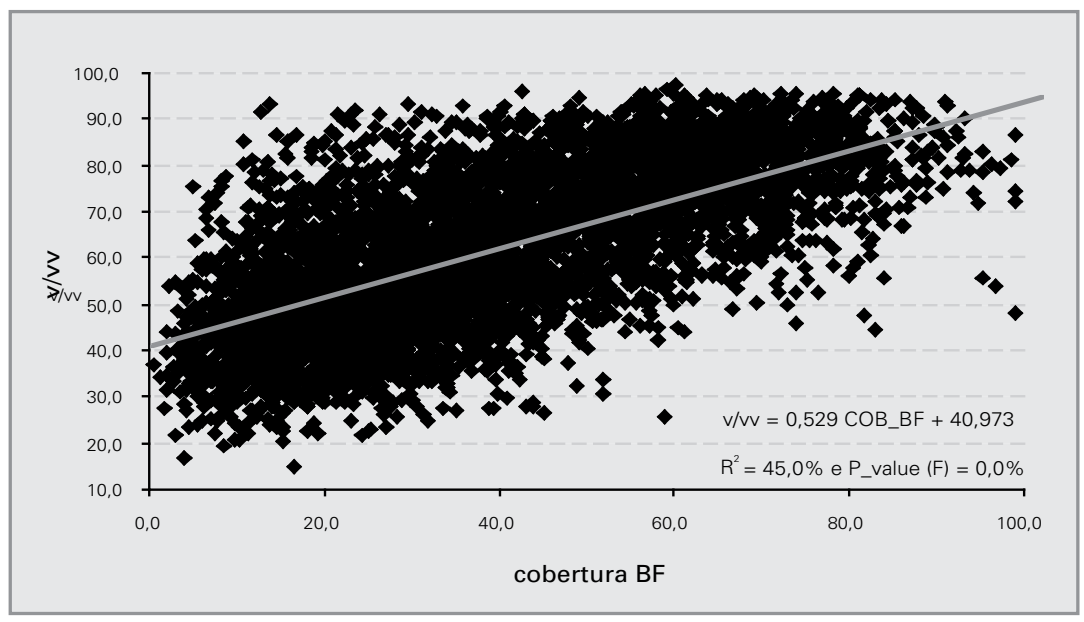

Gráfico 3

Relação do grau de cobertura do Bolsa Família na população total e votos válidos em Lula no segundo turno das eleições de 2006, nos municípios, segundo faixas de cobertura - \%

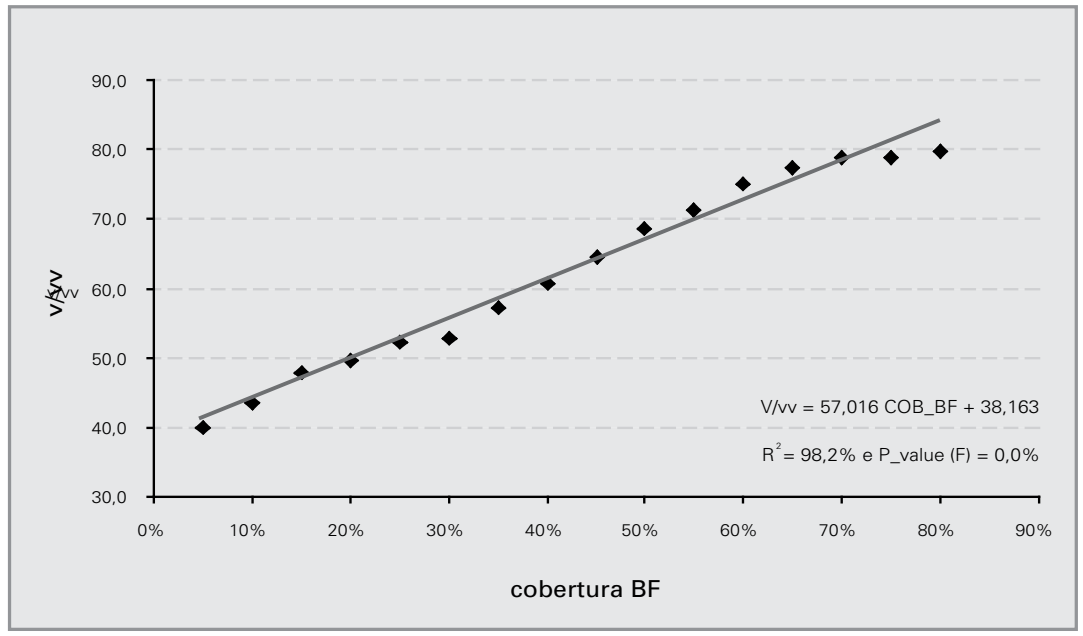

Fonte: STE e MDS 
Contudo, esse resultado deve ser assumido com cuidado, pois desconsidera outras influências. Ao se agrupar os municípios pelo nível de cobertura em relação à população total, eliminando as diferenças dentro de cada agrupamento, pois se utiliza a sua média, a relação é crescente. Em outras palavras, a diferença entre os Gráficos 3 e 2 é a eliminação da dispersão em torno da média.

\section{Influência conjunta de todos os fatores explicativos}

O resultado da regressão múltipla, para controlar a capacidade explicativa da cobertura do PBF em relação à população total sobre o resultado da eleição, indicou que mesmo sendo todos os fatores considerados estatisticamente confiáveis, a variável grau de cobertura é a mais relevante. Enquanto na regressão múltipla, integrada pelos oito fatores, o poder explicativo foi de $58 \%$, na regressão simples, com apenas o grau de cobertura do PBF, foi de $45 \%$, revelando a importância individual desta variável.

\section{CONCLUSÕES}

A pesquisa indicou forte relação entre o voto em Lula no $2^{\circ}$ turno e o peso do PBF na população total de cada município. Quanto maior a faixa de cobertura em relação à população total, maior a proporção de votos válidos recebidos. Mesmo quando os municípios não são agregados em faixas de cobertura, sendo o grau de dispersão bastante significativo, o PBF explica, sozinho, $45 \%$ dos votos.

As características dos municípios: predominância rural ou urbana; capital; participação do município em região metropolitana e interior; porte populacional; administração municipal do PT ou não e peso do eleitorado na população total, não influenciaram significativamente a relação entre a decisão do voto e o grau de cobertura do PBF. Já o IDH-M e a renda per capita, quando analisados qualitativamente, apresentaram capacidade explicativa relevante, mas inferior à do grau de cobertura.

A regressão múltipla realizada, com vista a controlar a relação do grau de cobertura sobre o resultado da eleição, composta de oito variáveis, mostrou capacidade explicativa de $58 \%$. A regressão simples do grau de cobertura com os votos em Lula, sozinha, indicou um poder explicativo de $45 \%$.

Assim, foi determinante para o resultado do pleito presidencial de 2006 o fato de o PBF abranger mais de 11 milhões de famílias e beneficiar quase $26 \%$ da população. Esses dados indicam que, mais do que uma percepção de uma política governamental, as famílias beneficiárias e seu entorno vêem o PBF como algo concreto, que alterou sua condição de vida. O presidente Lula, ao levar essa política para os municípios brasileiros e ao introduzir, no interior do PBF, um componente fixo, sem condicionalidade que não a pobreza, assegurou uma ampla base de apoio eleitoral. No momento do voto, a epígrafe deste artigo tornou-se uma reali- 
dade, embora Jacob Gorender tenha escrito essas linhas em outro contexto e com outro intuito.

\section{REFERÊNCIAS BIBLIOGRÁFICAS}

BRESSER-PEREIRA, L. C. - Equação do segundo turno. Folha de São Paulo, 09/10/06.

CARREIRÃO, Y. S. A decisão do voto nas eleições presidenciais brasileiras. Rio de janeiro: Fundação Getulio Vargas, 2002.

GORENDER, J. Hegemonia Burguesa - Reforçada pela Prova eleitoral de 94. In: Crítica Marxista. São Paulo, Editora Brasiliense, volume 1, $\mathrm{n}^{\circ} 2$.

LAMOUNIER, B. O Voto em São Paulo, 1970-1978. In: LAMOUNIER et al.; Voto de desconfiança: eleições e mudança política no Brasil, 1970-1979. Petrópolis: Ed. Vozes, 1980.

LIMA JUNIOR, O. B. Eleições presidenciais: centralidade, contexto e implicações. Revista Brasileira de Ciências Sociais, junho, vol. 14, nº 14., p. 11 - 30, 1999.

MARQUES, R.; MENDES, Á. O Social no Governo Lula: a construção de um novo populismo em tempos de aplicação de uma agenda neoliberal. Revista de Economia Política, volume 26, no 1 (101), janeiromarço, p. 58-74, 2006.

Desvendando o social no governo Lula: a construção de uma nova base de apoio In: Adeus ao Desenvolvimento. Belo Horizonte : Autêntica, 2005, p. 143-170.

MARQUES, R., MENDES, A.; LEITE, M. G. e HUTZ, A. A Importância do Bolsa Família nos municípios brasileiros, relatório de pesquisa. MDS, DF, 2004.

MARQUES, R., MENDES, A.; LEITE, M. G. e JANSEN, M.R. O Bolsa Família e o BPC: cobertura e importância nos municípios. Relatório de pesquisa. MDS, Brasília, 2006.

MARX, K. Contribuição para a crítica da economia política. Lisboa: Estampa, 1973.

MINISTÉRIO DA SAÚDE - Avaliação do Programa Bolsa Alimentação - Estudo 2: Análise de Impacto Preliminar. Brasília, Ministério da Saúde, 2003.

MINISTÉRIO DO DESENVOLVIMENTO AGRÁRIO. Balanço MDA 2003-2006. Disponível em http:// www.mda.gov.br/index.php?sccid=1322. Acesso em 15/03/07.

PEREIRA, C; RENNO, L. O que é que o reeleito tem? Dinâmicas Político - Institucionais Locais e Nacionais nas Eleições de 1998 para a Câmara dos Deputados. Dados, vol 44, nº 2, Rio de Janeiro, 2001.

RÊGO, J. As bases socioeconômicas dos partidos políticos no BRASIL: 1982-1990. Tese de mestrado em Ciência Política. UFPE. Recife, 1993.

RODRIGUES, L.M. Partidos, ideologia e composição social. Revista Brasileira de Ciências Sociais, vol. 17, $\mathrm{n}^{\circ}$ 48, fevereiro de 2002. São Paulo, ANPOCS, 2002.

SANTOS, B. S. - Lula e a esquerda. Folha de São Paulo, São Paulo, p.3, 22 set. 2006.

STEDILE, J. P. The Neoliberal agrarian model in Brazil. Monthly Review, vol. 58, nº 8, february 2007. New York, 2007.

ULYSSEA, G. www.unicamp.br/unicamp/canal_aberto/cliipping/maio2006. Acesso em 30/05/06. 